\title{
REPUBLICANISMO, LIBERALISMO E RACIONALIDADE
}

MARCUS ANDRÉ MELO

A teoria democrática contemporânea ramificou-se nos anos 70 e 80 em diversas teorias rivais. Neste ensaio discuto o conceito de racionalidade presente em três dessas teorias: republicanismo, liberalismo e escolha racional. O foco da discussão são as concepções republicanas, cujos microfundamentos ou concepções de racionalidade, que eu saiba, não foram ainda objeto de análises sistemáticas. Entendo que essa discussão é importante porque o republicanismo vem sendo um conceito cada vez mais invocado e suas diferenciações internas tornam-se cada vez maiores. Por economia de exposição, e por serem já bastante conhecidas, não farei uma exposição sistemática em separado do liberalismo e da escolha racional. A estratégia que adoto neste texto é de expor sistematicamente as teses republicanas e por contraste apontar as divergências com aquelas duas correntes teóricas.

Em ensaio instigante, Elster (1997) identificou o que seriam três vertentes fundamentais e discutiu seus pressupostos e programa de pesquisa. De uma parte estão as contribuições associadas à tradição schumpeteriana e à teoria da escolha racional (embora ele não acredite que a primeira se englobasse nesta última). ${ }^{1}$ Esta vertente representaria a política como um mercado: um mecanismo de agregação de preferências. De outra parte se situariam as concepções de democracia deliberativa, a política como fórum: um mecanismo de transformação de preferências mediante

\footnotetext{
1 Como corretamente assinala Elster no mesmo ensaio, a discussão da "vontade manufaturada" por Schumpeter, onde as preferências dos eleitores são moldadas pelos políticos torna sua análise incompatível com a noção de escolha racional.
} 
deliberação racional. Escapou-lhe no entanto a emergência, nesse mesmo período, das contribuições associadas à teoria republicana da democracia para além de alguns autores clássicos. $\mathrm{O}$ republicanismo tem sido crescentemente discutido como alternativa importante ao liberalismo. A discussão dessas teorias por Elster é rápida - não poderia deixar de sê-lo pelo número reduzido de contribuições existentes quando escreveu ${ }^{2}$ - e excessivamente centrada em um só aspecto: a questão da legitimidade. Aqueles que vêem a participação política como um bem em si mesmo - o que chama de objetivos secundários ou derivados (by-products) da democracia - incorrem em contradição grave. Se a democracia não pode ser sustentada e defendida por algum critério independente, ela não poderá sê-lo por critérios derivados. No presente texto considero as divergências de fundo entre as várias abordagens republicanas, sobretudo em termos de pressupostos subjacentes de racionalidade, e as discuto em relação às concepções da política como mercado e como fórum.

Meu objetivo é, após delinear de forma rápida e sumária os contornos fundamentais do republicanismo, basicamente discutir em que medida elas são subsumíveis em um dos dois pólos analíticos identificados por Elster. Por outro lado, pretendo explorar também em que medida essa concepção é consistente com as principais correntes do liberalismo contemporâneo, representadas por Rawls e Dworkin. Duas conclusões são discutidas ao final do trabalho. A primeira é que dois conceitos de racionalidade estão presentes no chamado republicanismo: o primeiro ligado à idéia de humanismo cívico e o segundo à idéia do republicanismo clássico ou tese republicana clássica. Enquanto o primeiro é incompatível com uma concepção instrumental de racionalidade, o segundo abriga tal noção de forma ampla, e é irreconciliável com o individualismo metodológico da escolha racional. A segunda conclusão é que, enquanto o republicanismo clássico é consistente com o liberalismo rawlsiano e dworkiano, o mesmo não vale para o humanismo cívico.

\section{REPUBLICANISMO: NEM MERCADO NEM FÓRUM?}

As interpretações republicanas de questões centrais da teoria democrática têm atraído grande interesse analítico, e é com frequiência

2 Na realidade, Elster refere-se a Mill, Pateman e Arendt. A sua exposição sobre republicanismo em Elster (1997), na realidade, é uma reprodução de uma seção de Elster (1983, pp. 91-101). 
cada vez mais maior que os conceitos de república e de valores ou virtudes republicanas são utilizados no léxico político. No entanto, porque suas fontes fundamentais não estão em autores contemporâneos - dos quais parecem existir apenas contribuições esparsas - , o republicanismo contemporâneo não adquiriu o status de teoria rival mais ou menos acabada na teoria política. A exposição que se segue é bastante seletiva e parcimoniosa, centrada na exposição das teses republicanas por autores díspares como Skinner, Taylor e Pettit e no debate interno entre suas posições. Desconsiderarei os estudos históricos e as fontes históricas do republicanismo, ${ }^{3}$ não só por questões de especialização, mas sobretudo porque o foco da questão é dado pelos conceitos de racionalidade subjacentes.

O ponto de partida para a discussão do republicanismo é o conceito de liberdade, ou mais especificamente o conceito de liberdade negativa, ao qual os republicanos se opuseram historicamente. Este conceito emergiu em oposição ao republicanismo clássico, e se define fundamentalmente como definindo a liberdade como ausência de constrangimentos ou obstáculos. Essa fórmula hobbesiana representou o núcleo duro a partir do qual se constituiu a tradição liberal clássica.

Berlin (1969) estabeleceu distinções finas entre os dois conceitos de liberdade - negativa e positiva - e ao mesmo tempo defendeu o conceito de liberdade negativa como o elemento nucleador da concepção de liberdade: os defensores da liberdade negativa querem limitar a autoridade como tal, enquanto seus opositores a querem em suas mãos. Para Berlin não se trata de duas interpretações de diferentes de um só conceito mas de "duas atitudes profundamente divergentes e irreconciliáveis quanto às finalidades da vida" (1969, p.166).

Na mesma linha afirma que “a questão ‘quem me governa?' é logicamente distinta da pergunta 'até que ponto o governo interfere comigo'?" (Berlin 1969, p.130). ${ }^{4}$ A idéia de "irreconciliabilidade" é central na argumentação de Berlin, que caracteriza os trade offs entre a liberdade positiva e a negativa como escolhas trágicas. Os defensores da liberdade

\footnotetext{
3 As referências essenciais são os trabalhos historiográficos de Pocock e Skinner - que não serão resenhados aqui

4 Ou de outra forma: "O sentido 'positivo' da liberdade vem à luz se tentarmos responder à pergunta não "o que estou livre para fazer ou ser'?, mas sim 'por quem sou governado?' ou 'quem vai dizer o que sou, vou ser ou fazer?'(P. 130). A tradução brasileira do texto é totalmente incorreta nesse e em outros pontos essenciais do texto. O mesmo vale para Rawls (1979).
} 
positiva padecem do que chama "monismo", ao reduzir as duas dimensões a um princípio ou valor. A idéia de tornar-se livre a partir da participação ativa e do autogoverno, conectando dever com interesses, eqüivale para Berlin a "arremessar um cobertor metafísico sobre o auto-engano ou a hipocrisia deliberada" (Berlin 1969, p. 196).

Em seu texto original Berlin conclui que "o pluralismo, com a medida de liberdade 'negativa' que traz em si, parece-me um ideal mais humano e mais verdadeiro do que as metas daqueles que buscam, nas estruturas grandes, disciplinadas e autoritárias, o ideal do autodomínio 'positivo' por classes, por povos, e pelo conjunto da humanidade" (Berlin 1969, p.171). Mais importante, para ele a noção de liberdade positiva está intrinsecamente articulada com a idéia de que os indivíduos devem agir de certas formas específicas de auto-aperfeiçoamento (individual ou coletivo), e que eles podem ser coagidos a persegui-las para que sua liberdade real ou superior possa ser efetivamente alcançada.

A sustentação por Berlin de que os indivíduos podem desfrutar de liberdade sob um déspota tolerante representa o argumento simétrico e ponto de partida para a crítica republicana. "A liberdade neste sentido [negativo], pelo menos do ponto de vista da lógica, não está relacionada com democracia ou auto-governo". Ou em outro lugar: "A relação entre democracia e liberdade individual é bem mais tênue do que pareceu a muitos defensores de ambas" (1969, p.130)

Com exceção do anti-utilitarismo radical de Berlin e de sua desconfiança dos especialistas, a argumentação anterior equivale, em larga medida, a uma defesa eloqüente da democracia representativa pluralista das poliarquias do pós-guerra. É também consistente - embora não inteiramente redutível a - com o ideal schumpeteriano de governo de elites políticas e burocracias especializadas na qual a "democracia significa apenas que o povo tem a oportunidade de aceitar ou recusar as pessoas designadas para governá-los" (Schumpeter, p.284-285).

Quando Schumpeter defende sua teoria da representação afirmando que "os eleitores de fora do parlamento devem respeitar a divisão de trabalho entre eles e os políticos que elegem", não está necessariamente abdicando do controle social, mas está assumindo esse imperativo de divisão de trabalho em virtude do fato de que os eleitores não têm opinião formada sobre a maioria das coisas e que nas democracias de massa os eleitores respondem a uma competição pela liderança política. A democracia define-se de modo procedimental e não pelos objetivos maximalistas aos quais supostamente deveria conduzir. A idéia de um controle social 
direto e extensivo é estranha a essa concepção: "Entre as eleições [os eleitores] não devem retirar a sua confiança muito facilmente e devem entender que, uma vez que elegeram um indivíduo, a ação política é deste e não deles. Isto significa que devem evitar instruí-los sobre o que devem fazer" (1975, p.295).

Para os defensores de uma concepção republicana, pelo contrário, o autogoverno e envolvimento com a res publica é precondição para a democracia. As liberdades negativas só estão asseguradas por uma cidadania ativa e mobilizada. Não perceber que as duas liberdades constituem faces da mesma moeda é uma falha da tradição liberal que vem de seu período formativo. Para Skinner (1993) os teóricos liberais assumem um mecanismo de mão invisível. ${ }^{5}$ Se todos perseguirmos nossos interesses próprios o resultado será o bem estar da comunidade como um todo. Do ponto de vista da tradição republicana, "esta é uma outra forma de descrever a corrupção", cuja superação é uma condição para a maximização de nossa liberdade individual. Sua análise está marcada pela discussão do republicanismo, sobretudo naquele pensador que mais claramente o exprimiu, Maquiavel. Em Skinner (1984), a história é utilizada instrumentalmente para a construção de uma crítica às concepções negativas de liberdade e a construção de uma alternativa conceitual. Preliminarmente, devese enfatizar que Skinner, em seus trabalhos históricos, chamou a atenção para um aspecto digno de registro: o fato de que as interpretações da liberdade dos antigos por Constant e Berlin são incorretas. Embora tenha se originado na Grécia o republicanismo é fundamentalmente neo-romano, e não se assenta exclusivamente na participação e cidadania ativa mas em um desenho institucional específico de checks and balances (Constituição mista). A questão que me interessa mais centralmente, no entanto, é a concepção de racionalidade subjacente à participação ativa dos cidadãos segundo o republicanismo.

Insurgindo-se contra aqueles que enxergam lixo metafísico nas concepções de liberdade que não estejam ancoradas nas liberdades individuais, ele insiste em demonstrar que o conceito de dever pode ser deduzido do conceito de interesse. Embora este último conceito não esteja te-

5 Essa acusação é feita mesmo em relação a Rawls. Para além de uma convergência geral entre o republicanismo e as concepções de Rawls e Dworkin, há divergências em vários níveis - como será discutido neste texto. Para uma referência crítica à primazia dos direitos sobre deveres em Dworkin, cf Skinner (1993. p. 307.) 
matizado claramente em Maquiavel, a idéia de racionalidade individual está subjacente a toda sua análise. Para o republicanismo, virtudes tais como coragem, temperança e prudência, juntamente com o envolvimento ativo com a esfera pública, são pré-condições para a preservação das liberdades individuais. ${ }^{6} \mathrm{O}$ cidadão prudente reconhece que a extensão das liberdades negativas que desfruta só pode ser o resultado ou a recompensa para a busca do bem público às expensas do interesse privado individual. Para essa variedade de republicanismo a razão básica para os indivíduos cultivarem virtudes e servirem o interesse público não é a noção de dever. $\mathrm{O}$ paradoxo de deveres qua interesses se desfaz com a concepção racional de natureza humana que está pressuposta em Maquiavel: "A não ser que se conceda razões egoístas aos homens, que são maus por natureza, para que se comportem virtuosamente, é improvável que qualquer um deles irá se engajar em ações virtuosas" (Skinner 1984, p. 219).

Em Skinner (1993) essa concepção de racionalidade da ação humana é ambígua. Embora ele afirme não querer defender abertamente a idéia de uma concepção perfeccionista da pessoas morais, a sua argumentação sugere uma defesa velada de ideais de florescimento ou excelência humana. Seu argumento explícito é de que a idéia de que seja necessário identificar um conteúdo objetivo, não-metafísico, para a idéia de florescimento humano é um pressuposto comum do debate sobre a questão, nisso concordando tanto Berlin quanto Taylor, com a diferença de que o primeiro nega que isso seja possível. No entanto esse pressuposto está equivocado, sustenta, na medida que é possível encontrar razões objetivas, plausíveis, que não recorram à idéia de finalidades humanas. Ao longo da argumentação, contudo, ele deixa entrever que a discussão nestes termos também é legítima.

A discussão sobre se é racional ser moral, sustenta, é uma questão genuína e central da filosofia moral. Nesta visão nós somos pessoas morais comprometidas pela nossa própria natureza com certos fins normativos. "Podemos querer argumentar que essa teoria da natureza humana é falsa. Mas dificilmente poderíamos argumentar que sabemos $a$ priori que ela nunca poderia ser em princípio sustentada" (p. 298). Se nós

\footnotetext{
${ }^{6}$ Seria correto considerar que a concepção schumpeteriana prescinde totalmente de virtudes? Acredito que não. Ele próprio reconhece isto ao falar que o autocontrole democrático implica em virtudes morais de um tipo negativo: não só a virtude da subordinação voluntária a decisões legais que emanem de autoridades competentes, mas também civilidade na apresentação de propostas legislativas e renúncia à tentação de transtornar o governo sempre que a oportunidade se apresentar (Schumpeter 1975, p. 294).
} 
necessitamos nos envolver com um certo tipo de sociedade de forma a nos tornarmos mais realizados, podemos imaginar tensões entre nossos interesses aparentes e os deveres necessários para que nossa natureza possa florescer. Mas, como afirma, dificilmente essa argumentação pode ser considerada paradoxal.

\section{SKINNER, PETTIT, TAYLOR}

Skinner reformulou sua concepção de liberdade negativa recentemente (Skinner 1999) - embora a base motivacional instrumental continue a mesma. Ele reconhece ter assumido erroneamente que a diferença entre os republicanos e seus críticos liberais clássicos não era apenas uma divergência sobre o significado da liberdade, "mas apenas sobre as condições que devem ser cumpridas para que a liberdade seja assegurada". ${ }^{7}$ Se não pode existir liberdade sob um tirano tolerante não-interventor, o seu simétrico não é verdadeiro: que poderia haver perda de liberdade sob uma intervenção consentida ou não arbitrária. A chave da questão torna-se então a questão da não arbitrariedade ou ausência de dominação (Pettit 1997).

Pettit inverte a discussão de liberdade negativa, tematizando-a como não-dominação. Para ele, esse conceito seria o traço distintivo do republicanismo. A liberdade republicana, ao contrário do que se encontra difundido na literatura, não se confunde com a liberdade positiva. O conceito de não-interferência é o conceito liberal clássico que reduz a liberdade à concepção negativa, admitindo, portanto, liberdade sob condições de não interferência mas sob subjugação ou dominação. A especificidade do republicanismo é considerar como não danosa a interferência não arbitrária. Para Pettit, ao contrário do que sustentaram Hume e Bentham, que introduziram um desvio na tradição republicana, as leis democráticas e não arbitrárias representam paradigmaticamente esse tipo de situação de interferência não-dominadora. Pettit insiste em que essa argumentação não endossa uma visão rousseauniana de que submissão à lei significa emancipação. Envolve uma recusa em aceitar a equivalência entre o modo de restrição da liberdade através da lei não arbitrária e a usurpação ilegítima. Esta formulação de Pettit permanece, acredito, pouco persuasiva. Não há

${ }^{7}$ Skinner (1999, p.62). Ele afirma que essa reformulação deve-se às críticas de Pettit. 
como distingui-la, neste ponto específico, das visões de liberdade positiva criticadas por Berlin.

Que diferenças existem entre o republicanismo de Skinner e o de Pettit? A primeira diferença está na aceitação da visão de liberdade como não interferência - recusada pelo segundo pelas razões expostas cuja obtenção só seria alcançada através da cidadania ativa. A segunda é a base motivacional da participação dos cidadãos. Para Skinner as liberdades negativas constituiriam o móvel da ação dos cidadãos; para Pettit, este móvel é a não-dominação. Esta parece ser sua posição, embora ele não deixe claro este ponto em sua longa exposição do republicanismo. Para Pettit (1999, pós-escrito) a principal diferença de sua posição frente à de Skinner é que para ele a liberdade para os republicanos é uma questão de dominação - há uma prioridade léxica de dominação em relação à nãointerferência. Para Skinner é igualmente uma questão de dominação $e$ de não-interferência. ${ }^{8}$

Taylor contesta a discussão da liberdade negativa em uma chave bastante distinta de Skinner. Para ele, esse autor define incorretamente a liberdade como o que chama valor convergente: são as virtudes do interesse próprio que justificam a concepção positiva de liberdade. $\mathrm{O}$ alinhamento entre interesse individual e coletivo é invocado como conferindo plausibilidade a esta última (Taylor 2000, p. 208). Daí Taylor esforçar-se em distinguir a tradição cívico-humanista do que denomina "tese republicana" articulada por Skinner. Essa tradição está assentada em uma visão não instrumental do envolvimento nos negócios públicos, enquanto a tese republicana recorre a uma concepção de racionalidade instrumental.

Taylor caracteriza a noção de liberdade negativa como um conceito de oportunidade (opportunity-concept): a ausência de obstáculos externos potenciais ou interferências às ações dos indivíduos mesmo que elas não sejam realizadas. A liberdade positiva consiste em um conceito de exercício (exercise-concept) (Taylor 1979).

A construção do argumento liberal contra a liberdade positiva, segundo Taylor, desenvolve-se em dois estágios. Em primeiro lugar, passase da noção de liberdade para fazermos o que queremos para a liberdade para fazermos o que realmente queremos, ou obedecermos nossa real von-

8 "Se Skinner estiver correto significa que os republicanos não terão nenhuma razão para preferir um regime onde há interferência sem dominação a um regime onde há dominação sem interferência." (id. ibid. p. 301) 
tade ou dirigirmos verdadeiramente nossa vidas. O passo seguinte é a introdução de alguma doutrina a respeito que supostamente revele como não podemos fazer o que realmente queremos, ou seguir nossa vontade efetiva, a não ser no quadro de certas formas canônicas de auto-governo. Resulta que só podemos ser livres nessas sociedades e que a liberdade equivale ao auto-governo coletivo segundo essa formas canônicas. Para ele, o liberal pára no primeiro estágio. No entanto, a idéia de auto-realização - que pressupõe a existência de um eu verdadeiro ou superior e um inferior ou falso - não pode ser descartada com base no argumento de que ela exigiria um imposição externa de preferências.

O conceito de liberdade como oportunidade e ausência de constrangimentos externos à ação é criticado por Taylor porque muitos obstáculos são internos e não externos. Assim, os indivíduos podem ter desejos irracionais que os impedem de realizar seus desejos superiores - como no caso de avaliações irracionais sobre riscos de decisões que permitirão aos indivíduos alcançar fins que julgam superiores. Os liberais da concepção negativa defendem corretamente que os indivíduos são o melhor árbitro de seus interesses e que, por extensão, não podem ser "forçados a ser livres", ou ter suas preferências verdadeiras identificadas ou selecionadas externamente. Insistem, segundo ele equivocadamente, na infalibilidade das preferências internas. Os desejos são de vários tipos, e podemos ter desejos sobre desejos ou metadesejos - identificáveis pelo que chama 'avaliação forte'. Os grilhões podem ser internos e a idéia de auto-realização implica sua remoção. Em outro nível, argumenta também que o próprio conceito de oportunidade é inconsistente para Taylor porque ter a oportunidade de ser livre já pressupõe o exercício da liberdade para remover as barreiras internas à liberdade. A liberdade implica ser capaz de reconhecer adequadamente meus objetivos mais importantes, e minha capacidade de superar ou pelo menos neutralizar meus grilhões emocionais, e ao mesmo tempo estar livre de obstáculos externos: "Mas claramente a primeira condição [o reconhecimento de objetivos] pressupõe que eu tenha atingido uma certa condição de discernimento e de auto-compreensão. Eu devo estar exercendo a auto-compreensão para poder ser verdadeiramente livre. Então eu não posso entender a liberdade apenas como um conceito de oportunidade" (p. 193).

Além disso o conceito de liberdade como ausência de obstáculos é inconsistente com o conceito pós-romântico de pessoa, subjacente à visão liberal moderna, que tem na auto-realização um dos seus princípios ordenadores. Neste ponto a concepção liberal de liberdade negativa é self- 
defeating, porque é contra-intuitiva em relação à sua própria noção de pessoa no liberalismo.

Taylor (2000) discute o republicanismo com base nos conceitos de patriotismo e bem comuns (em oposição ao de bens convergentes). ${ }^{9}$ "Bens comuns", ao contrário dos "bens convergentes" (que eqüivale ao "bens públicos" da terminologia microeconômica), são aqueles como a amizade, em que o que importa centralmente "é precisamente haver ações e significados comuns" (p. 206). O bem é aquilo que se partilha. Os bens convergentes são fruídos coletivamente (a segurança, etc), mas o caráter coletivo refere-se apenas ao fato de que sua provisão tem que ser pública ou coletiva em virtude da não-exclusão ou consumo não rival. A segurança como fim valorizado será sempre segurança para A, B ou C. Como argumenta, não é o caso de um bem distinto ou mais valorizado, porque ele é garantido coletivamente. Para Taylor, a "tese republicana" reduz a questão da liberdade a um bem convergente e não a um bem comum. A única maneira de defender minhas liberdades está no engajamento nos negócios públicos, uma vez que de outra forma estaria à mercê de outras pessoas que estão longe de prezar meus interesses. A "tese republicana", portanto, prescinde por inteiro de bens comuns, sendo a liberdade redefinida como bem convergente. Nela, a motivação das comunidades auto-governadas é resultado do medo da perda de liberdades, enquanto que para Taylor ela vem da solidariedade republicana ou de identificação patriótica profunda, cuja base é a existência de bens comuns.

Como vimos, esta argumentação é consistente com uma compreensão da natureza humana como dotada de propósitos associada a uma longa tradição na história do pensamento, notadamente no humanismo cívico. Cabe neste ponto esclarecer o ponto a respeito de sua consistência ou não com o liberalismo rawlsiano. A questão de fundo que separa a análise ralwsiana de autores republicanos como Taylor diz respeito ao conceito de sociedade. Para Taylor, e os críticos comunitaristas de Rawls, o agente em Rawls - ou mais propriamente self, diria Taylor - é desenraizado. Essa visão. que Taylor denomina "atomista", está assentada em um premissa de ação humana inadequada: o véu da ignorância não despe os indivíduos de aspectos contingentes mas de seus traços essenciais que os definem como pessoas. Este ponto será retomado na seção seguinte, pois permite um esclarecimento da relação entre o perfeccionismo dos republi-

\footnotetext{
9 Para economia de exposição não distinguimos entre os 'bens mediatamente comuns' dos 'imediatamente comuns'.
} 
canos (na crítica de Rawls) e o conceito de racionalidade. Taylor defende o que chama de ontologia holista no lugar do atomismo liberal: para ele os indivíduos são, para usar a sua terminologia, ontologicamente enraizados ou "situados" e não "libertos". Para essa defesa ele não precisa de argumentos morais ou políticos. Os indivíduos são capazes de "patriotismo" um meio termo entre a amizade (que tem o particular como objeto) e o altruísmo (que tem o universal como objeto) ${ }^{10}$. Essa identificação profunda os capacita a se sentirem ultrajados quando o bem comum é violado pela corrupção ou pelo uso privado da coisa pública. Esse ultraje não pode ser explicado por nenhum cálculo utilitarista. $\mathrm{O}$ modelo de capacidade ou dignidade dos cidadãos - ele usa os dois termos - dos liberais procedimentais está assentado no poder de reivindicar direitos e assegurar tratamento igual perante a lei, além da capacidade de influenciar decisões públicas através de tribunais ou instituições parlamentares. "O ideal não é 'governar e ser governado alternativamente', mas ter voz ativa”. Para ele isso é compatível com o não engajamento público, desde que se possa fazer ameaças críveis aos detentores do governo e forçá-los a ser responsivos. O modelo de capacidade dos cidadãos no republicanismo é bastante distinto:

[Esse modelo] define a participação no autogoverno como a essência da liberdade, como parte daquilo que tem de ser assegurado... Uma sociedade em que a relação dos cidadãos com o governo é normalmente antagônica, e mesmo onde estes conseguem fazer o governo render-se a seus propósitos, não garantiu a dignidade dos cidadãos, permitindo apenas um baixo grau de capacidade do cidadão. A plena participação no autogoverno apenas significa ter (...) alguma participação na formação de um consenso de governo, com o qual podemos nos identificar junto com outros. Governar e ser governado alternativamente significam que ao menos parte do tempo os governantes podem ser 'nós', não sempre 'eles'. Considera-se o sentido da capacidade do cidadão incompatível com uma nossa condição de partícipes de um universo político alheio que talvez possamos manipular, mas com o qual nunca poderemos identificar" (Taylor 2000, p.217).

10 É interessante notar que Dworkin (1989) faz a observação que o republicanismo não se confunde com o altruísmo que é a preocupação com o bem estar dos outros indistintamente, o interesse individual é percebido como dependente do bem da comunidade de que o indivíduo faz parte. 
Entre o modelo da participação ativa e o da "cidadania da via judicial" - centrado na defesa de direitos - Taylor prefere o primeiro.

\section{REPUBLICANISMO E PERFECCIONISMO}

Em que medida o republicanismo de Skinner e Taylor é consistente com a posição liberal de Rawls e Dworkin? Em que medida suas concepções de racionalidade são consistentes? O ponto de partida para essa reflexão é o conceito rawlsiano de justiça como eqüidade, e mais especificamente as liberdades básicas, e as relações entre o justo e as concepções do bem. Nessa variante do liberalismo o justo é anterior ao bem. Antes de discutir esse ponto essencial deve-se registrar que Rawls curiosamente não discute a questão da liberdade negativa versus positiva em sua Teoria da Justiça, por acreditar que a questão exigiria uma teoria do justo e da justiça. (Rawls 1999, p. 176). Para ele a controvérsia teria mais a ver com os valores relativos das várias liberdades quando conflitam entre si do que com definições distintas de liberdade.

Mas há seções da Teoria onde esta idéia já está presente, como quando ele afirma que, se alguém fosse forçado a escolher entre liberdades políticas e as outras, seria preferível o governo de um soberano que reconhecesse as liberdades de consciência e garantisse a prevalência da lei (Rawls 1979, p. 202). E neste contexto cita Berlin com aprovação, numa conclusão de que o mérito principal da participação seria garantir que os governos respeitassem os direitos dos governados. Mas essa conclusão é aquela de Skinner. Ele afirma curiosamente que a escolha entre os dois sentidos de liberdade não é um caso de tudo ou nada, mas um equilíbrio: devemos estreitar ou alargar a participação (liberdade política) até o ponto onde o perigo para as liberdades negativas "resultante da perda marginal de controle sobre aqueles que detêm o poder político compensa exatamente a segurança de liberdade obtida com o maior uso de dispositivos constitucionais".

Em outros lugares, no entanto, ele sustenta que falar de igualdades básicas iguais não significa que elas tenham que ser dispensadas ou valorizadas da mesma forma.

[A concepção de] justiça como equidade concorda com a linha de tradição liberal (representada por Constant e Berlin) que considera as liberdades políticas iguais [equal political liber- 
ties] (a liberdade dos antigos) como tendo em geral menos valor intrínseco que, digamos, a liberdade de pensamento e liberdade de consciência (a liberdade dos modernos). Isto significa, entre outras coisas, que, em uma sociedade democrática moderna, tomar parte contínua e ativa na vida pública geralmente tem, e certamente deve razoavelmente ter, um lugar menor na concepção do bem (completo) de muitas pessoas" (Rawls 2001a, p. 143).

Mas o cerne da inconsistência do liberalismo político com o republicanismo tem a ver com seu antiperfeccionismo e a forma como concebe as concepções do bem no marco da justiça como equidade. A questão do perfecionismo é tratada amplamente por Rawls na Teoria da Justiça. Por outro lado, a prioridade do justo é elaborada mais sistematicamente e até redefinida em Liberalismo Político. O perfecionismo é definido como qualquer concepção de excelências humanas ou de virtudes como princípios orientadores da ação que justifiquem o sacrifício de outras concepções por lhes serem superiores. É visto como teleológico na medida que postula um princípio único que dirige a sociedade a definir deveres e obrigações de modo a maximizar a perfeição das realizações humanas. É incompatível com a construção da posição original na medida que nela, sob o véu da ignorância, os indivíduos têm noções distintas sobre os ideais de perfeição, que não gostariam de por em risco como pessoas morais racionais. Eles não reconhecem um padrão único e portanto não podem por-se em acordo sobre esse padrão ou padrões (Rawls 1999, pp. 287-288).

A prioridade do justo em relação ao bem significa na prática que os interesses que exigem a violação da justiça não têm nenhum valor. Este ponto foi desenvolvido por Rawls em resposta à objeção de seus críticos de que a concepção de justiça como equidade em Teoria da Justiça era o que ele denomina doutrina abrangente, e portanto contraditória. A questão de fundo refere-se à questão da neutralidade liberal (termo que Rawls evita): o liberalismo mantém-se neutro em relação às concepções do bem das pessoas? Estas concepções podem ser abrangentes ou parcialmente abrangentes, isto é elas podem referir-se a um conjunto parcial ou amplo de questões morais, políticas e religiosas. Ou podem apenas ser gerais restritas a uma concepção política do bem. Dado o fato do pluralismo, o liberalismo admite apenas a esta última, e exclui as concepções não-razoáveis, ou seja aquelas que não são com- 
patíveis com a idéia de cidadãos considerados livres e iguais ${ }^{11}$ (o liberalismo político não ataca nem critica nenhuma visão razoável). A justiça como eqüidade não é portanto neutra no sentido procedimental. Seus princípios de justiça são substantivos e estão baseados em um "consenso sobreposto", isto é, numa base pública de justificação para o que Rawls denomina "estrutura básica" (as estruturas políticas e sociais da sociedade vistas como um sistema de cooperação).

O liberalismo político distingue-se portanto do liberalismo abrangente. que fornece respostas a questões que não são só políticas. Se a justiça como equidade implica, argumenta ele, menos chances de sobrevivência para algumas concepções do bem, é algo a que apenas devemos nos resignar, com base na idéia de que não há vida social sem perdas.

Considerando-se essa exposição sumária da posição rawlsiana com relação a estes dois pontos, passo a examinar em que medida ela é consistente com o republicanismo. A resposta vem do próprio Rawls. Como Taylor, ele diferencia o republicanismo clássico do humanismo cívico ${ }^{12}$. Define o republicanismo clássico como a visão segundo a qual, se os cidadãos em uma sociedade democrática pretendem preservar seus direitos e liberdades básicos, inclusive as liberdades civis que asseguram aquelas da vida privada, eles devem ter também um grau suficiente de "virtudes políticas" (como as chamo) e estarem dispostos a participar da vida pública. A idéia é semelhante à visão de Skinner: sem uma participação ampla de uma cidadania vigorosa e bem informada na política democrática até as instituições políticas mais bem intencionadas cairão nas mãos daqueles que procuram dominar e impor sua vontade por meio do aparato de Estado, por razões que variam ao longo do tempo. A segurança das liberdades democráticas requer a participação ativa dos cidadãos dotados das virtudes políticas necessárias para a manutenção do que chama regime constitucional. Em suas palavras:

Entendido o republicanismo clássico dessa maneira, a justiça como equidade, enquanto uma forma de liberalismo político, não tem nada a lhe opor. Pode haver, no máximo, certas diferenças sobre questões de molde institucional e da sociologia política dos regimes democráticos. Essas diferenças, se exis-

11 Estas idéias estão desenvolvidas nos ensaios "A idéia de um consenso sobreposto" (1987)

e "A prioridade do justo e as idéias do bem" (1988), reproduzidos em Rawls (2000)

12 Como representante desta última concepção Rawls refere-se a Hannah Arendt. 
tirem, nada terão de trivial: podem ser extremamente importantes. Mas não há uma oposição fundamental, porque o republicanismo não pressupõe uma doutrina religiosa, filosófica ou moral abrangente. Nada no republicanismo clássico, tal qual como caracterizado acima, é incompatível com o liberalismo político como o descrevi. ${ }^{13}$

Rawls insiste, no entanto, em que o liberalismo político não pode admitir o humanismo cívico. Este é entendido como uma forma de perfeccionismo aristotélico segundo o qual o homem é um animal social, ou político, cuja natureza essencial se realiza mais plenamente numa sociedade democrática através do engajamento na esfera pública. Ao contrário do republicanismo clássico a participação não é incentivada como algo necessário à proteção das liberdades básicas da cidadania democrática, ou como um bem entre outros. O engajamento nos negócios públicos é "considerado o locus privilegiado da vida digna de se vivida. Isso significa voltar a dar um lugar central àquilo que Constant chamava de 'liberdades dos antigos', e tem todos os seus defeitos." $14 \mathrm{O}$ republicanismo não representa, portanto uma concepção abrangente e portanto é consistente com o liberalismo político e com a concepção de justiça como igualdade que ele abriga (Rawls 2001a, p.144).

Em outro ponto argumenta que as liberdades políticas são tratadas de forma especial, tal como expressa pela garantia de seu valor eqüitativo, não "porque a vida política e a participação de todos no autogoverno democrático são consideradas bens proeminentes para cidadãos plenamente autônomos." 15 De modo consistente com o conceito de concepção política do bem, esboçado anteriormente, ele afirma que atribuir um lugar central à vida política é apenas uma concepção do bem entre outras. E mais: sustenta que nas sociedades contemporâneas, em virtude do próprio tamanho do Estado moderno, o exercício de liberdades políticas "está fadado a ter um lugar menor na concepção do bem da maioria dos cidadãos do que o exercício de outras liberdades fundamentais ${ }^{16 " . ~ O ~ f a t o ~}$

13 Do ensaio "As prioridades do justo e as idéias do bem”, de 1988, reproduzido em Rawls, 2000, p 254).

14 Id.ibid. pp. 253-254

15 id. ibid. p. 254

16 Do ensaio "as liberdade fundamentais e sua prioridade", de 1982, reproduzido em Rawls, 2000, p. 386. 
de que algumas pessoas realizem sua concepção do bem a partir da participação ampla e vigorosa na vida pública produz o bem da sociedade assim como o fazem as pessoas que usam seus distintos talentos em atividades de cooperação mútua. Neste ponto o argumento refere-se aos efeitos positivos da divisão de trabalho (2001a, p. 145). A participação dos cidadãos nas questões políticas, ou nas várias formas associativas não-políticas, são bens de grande importância, mas que fazem parte da gama de decisões individuais das pessoas.

Rawls aproxima-se neste ponto da visão de Berlin sobre o potencial opressor de uma sociedade excessivamente mobilizada, que pode facilmente ser interpretado como uma espécie de tirania da virtude:

Um homem pode afastar-se de um estado democrático vigoroso e genuinamente 'participativo', no qual as pressões sociais ou políticas sejam excessivamente sufocantes para ele, em busca de um ambiente onde haja menos participação cívica, mas mais privacidade, uma vida comunal menos dinâmica e menos abrangente, menos gregarismo, mas também menos restrições. Isto pode parecer indesejável para aqueles que têm aversão pela vida pública ou pela sociedade como um sistema de malaise e de profunda alienação (Berlin, 1969, p. 57)

Neste ponto cabe perguntar qual o papel das virtudes - questão central para os republicanos - no liberalismo político. Há lugar para as virtudes no liberalismo político? A resposta é positiva. Certas formas de caráter moral são superiores e devem ser encorajadas - a civilidade, a cooperação social eqüitativa, etc. Mas isto não implica um estado perfecionista de uma doutrina abrangente. Pois essas virtudes políticas distinguem-se daquelas que caracterizam formas de vida que fazem parte de concepções morais e filosóficas abrangentes. Distinguem-se também das formas de vida vinculadas a ideais associativos, à vida familiar ou às relações privadas entre indivíduos.

Seria um erro, com efeito, entender o liberalismo político como privatista e hobbesiano. Na realidade, um seus valores fundamentais é o de razão pública (o outro sendo os valores da justiça política). Esta é entendida justamente como as diretrizes da indagação pública que tornam essa indagação pública e livre, juntamente com as virtudes que ajudam a tornar possível a discussão pública. Essa indagação (inquiry no original) refere-se à investigação e debate de uma questão pública. A razão pública não deve 
ser entendida intuitivamente como tendo o seu oposto a razão privada pois como sustenta Rawls "uma razão privada é coisa que não existe" (2000, p. 269), mas como algo aplicável à cultura política pública. Ela não se aplica à "cultura não-pública" da sociedade civil ou "cultura de fundo" nos seus termos. O locus da razão pública é perfeitamente delimitado: é o fórum político público composto do discurso dos juízes em suas discussões; o discurso dos ocupantes de cargos executivos e legisladores; e o discurso dos candidatos. ${ }^{17}$

Esta argumentação aproxima a argumentação rawlsiana da idéia da política como fórum - em oposição à política como mercado - referida no início deste artigo - mas ele permanece firmemente anti-republicano, pelo menos no sentido do humanismo cívico, pelas razões já expostas, e sobretudo pela sua ênfase em um espaço circunscrito para o uso da razão pública.

A argumentação de Dworkin em relação à neutralidade do Estado é distinta da de Rawls, mas leva a resultados semelhantes. A neutralidade é pensada em termos de igualdade de tratamento dispensado pelo Estado às pessoas como iguais. Sua teoria liberal da igualdade exclui quaisquer considerações perfeccionistas sobre visões do que é bom na vida. Em seus termos a moralidade constitutiva da liberalismo exige a neutralidade entre teorias sobre o que é valioso na vida. Portanto sua oposição ao humanismo cívico está ancorada neste ponto:

O liberalismo não se apóia em nenhuma teoria especial da personalidade nem nega que a maioria dos seres humanos pensará que o que é bom para eles é que sejam ativos na sociedade. O liberalismo não se contradiz: a concepção liberal de igualdade é um princípio de organização política exigido pela justiça, não um modo de vida para indivíduos, e para os liberais, como tais, é indiferente que as pessoas prefiram manifestar-se em questões políticas. ${ }^{18}$

Para Dworkin os direitos são anteriores aos deveres - em oposição à visão de que ambos são partes indissolúveis. (Dworkin 1977, pp.170-177) Essa é uma forma diferente de dizer que as liberdades negativas são mais importantes do que as liberdades positivas. A forma como

17 “A idéia de razão pública revisitada" (1996), reproduzido em Rawls (2001b)

18 Do ensaio "Liberalismo", reproduzido em Dworkin (2000, p. 303). 
Dworkin discute as virtudes é semelhante, em moldes gerais, à argumentação rawlsiana antiperfeccionista em relação às concepções do bem. Mas há aqui um visão mais negativa das virtudes. A idéia de virtude ou de uma sociedade virtuosa é vista como peça integral do conservadorismo em oposição ao liberalismo. A idéia de virtude para ele é um componente central da moralidade constitutiva do conservadorismo, com implicações importantes sobre as noções de igualdade e liberdade (Dworkin 2000, pp.296-299).

Dworkin (1989) é uma resposta aos críticos comunitaristas que questionaram sua posição quanto à neutralidade do Estado liberal. É curioso que ele indistintamente denomina os comunitaristas "republicanos cívicos". Isto não é de todo injustificado, pois comunitaristas importantes, como Sandel (1996, pp. 3-28), têm recentemente defendido o republicanismo e criticado o seu oposto, que ele denomina liberalismo procedimental. Os republicanos cívicos são para Dworkin os defensores da tese da integração, que ele define como a visão de que as vidas dos indivíduos e de suas comunidades são integradas e que o sucesso dos indivíduos e suas realizações são um aspecto dessas últimas e que portanto eles dependem do bem das comunidades. Para os comunitaristas o liberalismo desvaloriza as concepções abrangentes do bem quando recorre a idéia de um véu espesso de ignorância (cuja conseqüência é que as partes não conheçam as doutrinas abrangentes das pessoas) ou de neutralidade em relação às concepções do bem. Esses pressupostos em si já fazem parte de uma concepção liberal abrangente. Daí insistirem na indivisibilidade dos indivíduos e comunidades, e portanto na necessidade de uma concepção do bem. Por isso mesmo recusam uma ética do direito em oposição a uma ética do bem. Dworkin argumenta que é salutar insistir na dependência do bem individual do bem da vida comunal mas acha que ela tem limites e pode incorrer em "falácias antropomórficas". No argumento da integração a atitude que os indivíduos assumem em relação à sua vida individual aplica-se igualmente em relação à vida ética e moral da comunidade de que dependem. Se para os liberais, observa, a questão da liberdade sexual é posta em termos de se é legítimo impor convicções éticas a outrem, para os republicanos cívicos a pergunta converte-se na questão de se a vida comum da comunidade, de que eles tanto dependem, deveria ser saudável ou degenerada.

O republicanismo, argumenta, tem como unidade de análise a comunidade e apenas se pergunta como as decisões da comunidade sobre liberdade e regulação afetam a vida dos indivíduos. Essa é uma questão bastante distinta das situações do altruísmo ou do paternalismo, nas quais 
a unidade de análise é o indivíduo que expande suas preocupações para a comunidade. Ou do orgulho (ou falta dele) em relação às realizações de outrem. Para Dworkin isso sugere uma antropomorficação da comunidade, que passa a ser vista como ontologicamente anterior aos indivíduos. Em forte contraste com a análise de Taylor, o senso de pertença a um coletivo - uma orquestra, por exemplo - é discutido como resultando de práticas sociais concretas e não arbitrárias (como, por exemplo, um grupo de pessoas cuja única coisa em comum sejam seus nomes próprios), de natureza coletiva (a produção de música orquestral). Não há anterioridade ontológica desse coletivo em relação a seus membros.

Dworkin reconhece com os republicanos cívicos que os cidadãos identificam-se com sua comunidade política quando reconhecem que a comunidade tem uma "vida comunal", e que as realizações ou derrotas em seus projetos individuais são eticamente dependentes das realizações e derrotas da vida da comunidade. A diferença para Dworkin diz respeito à demarcação das fronteiras do que se entende como vida comunal em relação à comunidade política. Para ele estas fronteiras são restritas. Eles referemse apenas a "atos políticos formais": as práticas políticas coletivas envolvendo as atividades dos governos, as ações legislativas e judiciárias. A concepção antropomórfica vai além e inclui valores não-políticos. Mas apenas se a vida da comunidade se restringir "a decisões políticas formais, se o sucesso crítico de uma comunidade portanto depender só do sucesso ou falhas de suas decisões legislativas, executivas e judiciárias, é que podemos aceitar o primado ético da vida da comunidade sem abandonar ou comprometer a tolerância e neutralidade sobre o que é a boa vida" (Dworkin 1989, p. 502). Ele refuta a visão estereotipada da pessoa no liberalismo, segundo a qual ela, embora possua um senso de justiça, rejeita o ideal de integração com a comunidade: ela só fará pela comunidade o que seu sentido de justiça exige, mas não verá sua vida diminuída em valor se sua comunidade convive com fortes desigualdades sociais ou discriminação. Em seu lugar propõe o conceito do integrated liberal como o verdadeiro sentido do liberal. O liberal integrado reconhece uma diminuição do valor de sua vida se sua comunidade convive com tais desigualdades. A conclusão mais importante a que o autor chega é que "a fusão da moralidade política e o autointeresse crítico me parece ser o verdadeiro nervo do republicanismo cívi$\mathrm{co}$, a forma fundamental pela qual cidadãos individuais fundem seus interesses e personalidades na comunidade política".

Embora divirja de Rawls em pontos importantes, e a linguagem seja distinta, essa análise mantém forte similitude com a argumentação de 
Rawls em um sentido importante: a ênfase nos fatores exclusivamente políticos como fundamento de uma moralidade pública. Se em Rawls isso é alcançado com a idéia das concepções políticas (não abrangentes) de justiça ou do bem, do consenso sobreposto de natureza exclusivamente política, em Dworkin o equivalente é uma visão exclusivamente política da vida comunal da comunidade política.

Uma tentativa de definir o republicanismo de forma a conciliálo com o liberalismo foi proposta por Pettit em vários trabalhos (Pettit 1997). Pettit também endossa uma concepção antiperfeccionista: o republicanismo não admite "o estado perfeccionista que adota alguns bens específicos, sem considerar os interesses dos cidadãos". No entanto, ao contrário do liberalismo rawlsiano, sua moralidade é antideontológica e conseqüencialista. Pettit define o republicanismo como conseqüencialista porque nele a liberdade como não-dominação é um valor que o Estado deve promover, não um constrangimento que ele deve honrar. ${ }^{19}$

Taylor reconhece precisamente a fronteira que separa os liberais dos republicanos da tradição cívica. O liberais procedimentais tratam o autogoverno como mero instrumento do regime de direito e de igualdade. "Tratá-lo como o trata a tradição republicana, que o vê como essencial a uma vida de dignidade, como sendo em si o bem político mais elevado, nos faria ultrapassar as fronteiras do liberalismo procedimental" (p.216).

\section{A RACIONALIDADE NO REPUBLICANISMO E EM RAWLS}

Nesta seção passo a considerar o conceito de racionalidade, individual e coletiva, que está subjacente às idéias republicanas, estendendo a discussão para assinalar alguns aspectos do conceito de racionalidade em Rawls. Esforço-me apenas em oferecer respostas a duas questões colocadas inicialmente. A primeira é se é possível conciliar republicanismo, pelo menos no autores discutidos anteriormente, e escolha racional. Em outras palavras, as teorias de ação coletiva informadas pela escolha racional são consistentes com o conceito de participação política no republicanismo? A segunda é se os conceitos de racionalidade no republicanismo e

19 Para a complexa distinção entre honrar e promover nos marcos de uma ética consequencialista cf. Pettit (2001) 
no liberalismo rawlsiano são compatíveis.

A discussão que empreendo aqui é bastante parcimoniosa. Por racionalidade quero apenas considerar o que Elster (1983) denomina thin theory da racionalidade: racionalidade como consistência entre os desejos de um ator e seu sistema de crenças - as suas razões para agir de um certo modo ou tomar determinado curso de ação - e entre as razões e as ações empreendidas em função das mesmas. ${ }^{20}$ Deixo de lado várias dimensões importantes e controvertidas do conceito.

Como alerta preliminar devo registrar que, como assinalado, as concepções de racionalidade subjacentes às idéias dos autores republicanos citados são díspares. Discutirei primeiramente a questão da racionalidade individual. Para Skinner a ação coletiva é instrumental. Os cidadãos engajam-se em ação coletiva porque essa seria a forma pelo qual poderiam obter um bem que prezam: suas liberdades, ou a não interferência na esfera das liberdades básicas. Para Pettit, de forma distinta, as preferências dos cidadãos voltam-se para a busca da não-dominação. Essas visões são consistentes com a idéia de uma escolha racional. As ações empreendidas são consistentes com as crenças dos atores sobre como obter esses bens. A evidência histórica nas repúblicas estudadas parece fornecer evidências aos atores de que a melhor forma de evitar a tirania ou dominação consiste em uma vida pública ativa e participante. A história é invocada instrumentalmente, como reconhece Skinner (1984), para fornecer evidências empíricas de que os indivíduos podem considerar a participação como instrumental. A objeção de que essas evidências não são consistentes com os sistemas políticos contemporâneos é uma questão empírica e não teórica. Autores como Taylor e Skinner insistem sobre a consistência dessas crenças nas sociedades contemporâneas. Muito da argumentação sugere que a dominação temida nas sociedades republicanas cedeu lugar, nas atuais poliarquias, a um certo despotismo tecnocrático ou formas corruptas de governo nas sociedades modernas. A participação e autogoverno prestar-se-iam, dessa forma, a evitar que as preferências dos atores sejam distorcidas nessas formas pervertidas.

20 As preferências dos atores racionais devem também ser transitivas, completas e fixas. Elas devem ser capazes de escolher $x$ a $y$, ou serem indiferentes na escolha; ser objeto de um ordenamento do tipo se $x$ é preferível a $y$, e $y$ é preferível a $z$, então a é preferível a $z$; e não devem ser possíveis de mudanças (independente de algum processo de aprendizagem.que a teoria pode endogeneizar). Essas premissas asseguram possibilidade de previsão à teoria. 
Essa análise da ação coletiva é bastante distinta da análise ação coletiva associada a autores na tradição da escolha racional, como Olson, por várias razões. Em primeiro lugar, no que se refere à ação de grupos, ela não é consistente com o individualismo metodológico. Para Olson, a ação de grupos só pode explicar-se pela racionalidade dos indivíduos. A análise apresentada em Skinner e Pettit assume como dada a racionalidade de grupo. Embora sejam consistentes com uma concepção de racionalidade, elas não o são com o individualismo metodológico. A questão central para Olson (1971) é explicar quem se organiza. O ponto de partida é a racionalidade dos indivíduos, que os impele tendencialmente à inação mesmo quando existe comunalidade ou convergência de interesses com outros indivíduos. Quanto maior o tamanho do grupo tanto maior o desincentivo à ação coletiva, porque o monitoramento dos free riders torna-se crescentemente difícil. A ação coletiva tem custos individuais concentrados e benefícios difusos porque muitos bens que estão na agenda política têm características de bens públicos: seu consumo é não rival e não exclusivo e, uma vez ofertados, é impossível excluir alguém do seu consumo. Indivíduos racionais comportam-se estrategicamente para obter os bens que valorizam. Se podem obtê-los sem incorrer em custo algum eles tenderão a esperar que outros se mobilizem para obtê-los. A ação coletiva só ocorre, portanto, como subproduto da busca por bens privados, através da oferta de incentivos seletivos ou pela ação de political entrepreneurs - para os quais existem outros bens privados a serem desfrutados para além do bem público.

A idéia de comportamento ou racionalidade estratégica é logicamente distinta daquela relacionada à unidade básica de análise, se o indivíduo ou o grupo. Pode-se assumir, como Skinner e Pettit, que grupos podem comportar-se estrategicamente - ou seja instrumentalmente - para a obtenção de seus objetivos comuns. Este é o caso de autores filiados à escola da escolha racional, como Przeworski ${ }^{21}$, em que a questão é explorada para sindicatos, partidos ou grupos reformistas em situações de transição à democracia. Nesse caso, entendo, faz-se a assunção draconiana de que tais atores coletivos são atores unitários. ${ }^{22} \mathrm{~A}$ objeção fundamental é

21 Ver, por exemplo, suas análises das reformas econômicas e políticas na Europa do Leste e América Latina, ou seus estudos sobre a social democracia.

22 Elster continua insistindo que salvo em casos excepcionais o individualismo metodológico é o único modelo consistente com a escolha racional. Cf. sua crítica devastadora da escolha racional sem individualismo metodológico em Elster (2000). 
que tais atores se deparam internamente com o problema do cumprimento das regras para evitar a defecção individual - problema que em si replica, internamente, o problema de ação coletiva que enfrentam externamente.

A concepção de racionalidade dos autores republicanos discutidos também não envolve pressupostos comportamentais de maximização, optimalidade ou egoísmo. Os cidadãos republicanos adotam cursos de ação que os levam a alcançar seus objetivos, não necessariamente o melhor curso de ação, nem aquele que maximiza o seu bem estar individual. Assume-se, mais uma vez draconianamente, que eles se deparam com uma estrutura de incentivos em que suas preferências estão alinhadas com as da comunidade.

Passo a considerar agora como a racionalidade coletiva é tratada por estes autores. A racionalidade coletiva refere-se à tomada de decisão coletiva e aos resultados agregados das decisões individuais. É nesse ponto que a imagem da política como mercado se afirma mais claramente nos marcos da escolha racional. Essa questão não se coloca na argumentação republicana pelo próprio alinhamento de preferências que está pressuposto entre interesses individuais e coletivos. ${ }^{23}$ Não existe um problema de agregação, nem tampouco, por extensão, pode-se falar de efeitos não antecipados dessa agregação. Em certas variantes do republicanismo está implícita a idéia de deliberação. Uma discussão desse ponto escapa ao escopo deste ensaio. Quero ressaltar, no entanto, que a própria idéia de agregação pressupõe interesses individuais ou preferências que serão agregadas no processo político mediante algum mecanismo de escolha coletiva. Nas democracias esses processos de agregação envolvem um ou vários mecanismos majoritários.

A representação histórica, na teoria liberal desses processos, tende a ser negativa, como amplamente demonstra Berlin (1969), porque associada ao risco da tirania da maioria nas democracias. Como sabemos, a democracia foi pelo menos até o século XIX pensada como forma degenerada de regime. As salvaguardas das liberdades negativas foram pensadas historicamente em relação a este problemas e guardam a marca do constitucionalis-

23 Na realidade, a noção de racionalidade coletiva torna-se suspeita se involve um apelo à coletividade por cima dos indivíduos que a compõem, com base na renúncia das pessoas a seus interesses individuais em benefício de uma entidade coletiva mítica, como o povo ou a comunidade. Cf Elster 1983, p. 26. 
mo antimajoritário. No entanto as liberdades positivas foram pensadas como forma de emancipação política e como forma de identificação do interesse comum. Seja pela participação ativa, republicana, seja pela simples manifestação da maioria, não necessariamente importando em democracia direta, a democracia passou a ser vista como virtuosa e como um método de descobrir o bem comum ou o interesse coletivo. Segundo essa concepção epistêmica de democracia, este último existe e a democracia é o mecanismo que o revela (Przeworski 1999). A partir dos achados dos vários teoremas da impossibilidade, e pouco antes deles da crítica schumpeteriana à idéia de bem comum como falácia, variantes centrais da teoria democrática de inspiração liberal abandonaram essa concepção e concentraram-se na irracionalidade dos mecanismos majoritários a partir de argumentos técnicos oriundos da teoria da escolha social. ${ }^{24} \mathrm{Na}$ forma em que foi formulada por Arrow e outros, os métodos majoritários de agregação de preferências ou violam vários supostos importantes, como o princípio da não-ditadura (um ator não pode impor suas preferências sobre outros), ou estão sujeitos a problemas de instabilidade (maiorias cíclicas, etc).

Como os autores republicanos citados se colocam em relação à questão da racionalidade (coletiva, por definição) da democracia? Na realidade não existe uma resposta única. Taylor é o que mais se aproxima de uma visão epistêmica da democracia. Para a concepção republicana que defende, a participação ocorre e dá sustentação ao que chama de bens mediatamente comuns. A democracia republicana produz uma forma superior de racionalidade. Mas usar o termo racionalidade aqui talvez não inteiramente consistente com o uso de racionalidade coletiva que estamos utilizando quando falamos de situações que a teoria da escolha racional denominaria pareto-inferiores ou sub-ótimas. Porque, para Taylor, a mobilização dos cidadãos republicanos não produz conseqüências perversas não antecipadas, mas sim consequiências virtuosas. Sua racionalidade individual não é maximizadora e egoísta, portanto não surgem problemas de ação coletiva ou fenômenos tipo mão invisível.

24 Dahl (1956) é um tratamento pioneiro deste ponto. Ele discute quatro objeções técnicas à concepção populista da democracia como ele denomina o majoritarianismo, numa terminologia que ele atribui a Shils, e que se tornou mais difundida com Riker (1983). Dahl (1956, p. 34) afirma que Madison utiliza o termo 'republicano' para denotar majoritarianismo. Para Riker a instabilidade da regra majoritária deveria desautorizar proposições de engenharia política que correspondem a formatos populistas ou de democracia direta. 
Sob o risco de ser acusado de tratar muito apressadamente um tema demasiadamente complexo, mas para que o confronto com o liberalismo rawlsiano não fique incompleto, passo a considerar a seguir o conceito de racionalidade no liberalismo rawlsiano. A primeira advertência a ser feita, no entanto, é que não se trata de um confronto nos mesmos níveis, e a própria idéia de confronto deve ser substituída pela de discussão em níveis distintos de explicação, que são muito provavelmente incomensuráveis. Enquanto a discussão do republicanismo é feita em relação a referentes empíricos concretos, cidadãos das repúblicas italianas ou de democracias contemporâneas, a discussão de justiça com equidade é um construto mental, um recurso analítico. Rawls não se cansa de repetir isso. As referências à racionalidade e à escolha racional são abundantes na Teoria da Justiça. Um dos pontos em que esse conceito é mais explorado é em relação à racionalidade das partes na posição original. Nela os indivíduos, sob o véu da ignorância, fazem escolhas racionais. A própria racionalidade é assumida quando fazem escolhas sobre bens primários e em relação aos dois princípios de justiça.

Embora na Teoria da Justiça o conceito seja ambíguo ${ }^{25}$, Rawls em vários pontos de suas obras subseqüentes deixa claro que a noção de racionalidade que utiliza está longe do conceito de racionalidade instrumental ou estratégica associada à ciência econômica. Ele reconhece que

Aqui corrijo uma observação de Teoria... segundo a qual a teoria da justiça é uma parte da teoria da escolha racional. A partir do que acabamos de dizer, isso é simplesmente incorreto e implicaria que justiça como equidade é no fundo hobbesiana (da forma que Hobbes é freqüentemente interpretado) e não kantiana. O que deveria ter sido dito é que a interpretação das partes, e de seu raciocínio, usa a teoria da decisão racional, embora apenas de forma intuitiva. (Rawls 2001, 82).

Justiça como eqüidade não admite que a moralidade seja derivada da racionalidade. Os agentes de Rawls são racionais embora não egoístas: podem querer maximizar o interesse de outrem. Isto é consistente com a teoria da escolha racional no sentido thin da teoria. Mas eles são também 
razoáveis e dotados de um senso de justiça. Isto não significa altruísmo: eles não são movidos pelo bem comum mas apenas por um sentimento de reciprocidade em um mundo cooperativo. As partes na posição original são mutuamente desinteressadas - elas não se interessam pelo bem dos outros mas são dotadas de um senso de justiça. Mas no seu construto teórico o componente que exclui qualquer racionalidade auto-interessada em um plano empírico, e portanto qualquer comensurabilidade com a noção de racionalidade dos agentes republicanos, é a noção do véu da ignorância. Este despe os indivíduos de quaisquer referências empíricas, colocando-os em um nível de racionalidade universalizante, que deve, no entanto, ser distinguido de um cálculo racional sob incertezas - como ele próprio sugere ainda que de modo ambíguo, e como entenderam seus primeiros críticos utilitaristas.

O mais importante a ser ressaltado, todavia, é que a argumentação rawlsiana é um esforço construtivista de definição de um conceito de justiça. Ele não é uma descrição de "nenhum processo político concreto e muito menos da forma como um regime constitucional funciona" (Rawls 2000, p. 397).

Rawls recusa em muitos lugares qualquer analogia entre o processo político e o mercado. Para ele uma peculiaridade do processo de mercado ideal, que é distinto do processo político ideal, conduzido por legisladores imparciais e racionais, é o fato de que o mercado alcança um resultado eficiente mesmo que todos busquem seu próprio benefício (Rawls 1979, p. 316). Para além da analogia superficial entre mercados e eleições, o mercado ideal e o procedimento legislativo ideal divergem, para ele, em aspectos cruciais. O mercado conduz à eficiência, enquanto a deliberação política conduz idealmente à justiça. Mas, embora o mercado competitivo conduza invariavelmente à eficiência, a deliberação não necessariamente produz resultados que os agentes consideram justos. A discussão legislativa deve ser concebida não como um competição de interesses mas como a busca da melhor política definida pelos princípios de justiça. Como a conduta humana é informada por um senso de justiça, o homem econômico não representa adequadamente o processo. Na análise econômica não se considera a razão porque os compradores e os vendedores se comportam de acordo com as regras das leis que governam a atividade econômica; ou como as preferências se formam ou se estabelecem as normas legais. Em sua maioria estas questões são assumidas a priori. $\mathrm{Na}$ política, pelo contrário, não se pode assumir que as regras são dadas ou que serão seguidas (pp. 431-432). A política é a formação pública de preferên- 
cias ou deliberação. Esta discussão nos leva, todavia, para longe do foco deste trabalho.

MARCUS ANDRÉ MELO é professor do Departamento de Ciências Sociais e do Programa de Pós-Graduação em Ciência Política da Universidade Federal de Pernambuco. Acaba de publicar Reformas constitucionais no Brasil - Instituições políticas e processo decisório (Ed. Revan).

\section{REFERÊNCIAS BIBLIOGRÁFICAS}

BERLIN, Isaiah. (1969), Four essays on liberty. Oxford, Oxford University Press.

DWORKIN, Ronald (1977). Taking rights seriously. Harvard, Harvard University Press.

DWORKIN, Ronald (1989). "Liberal Community", California Law Review, 77-3, pp. 479504.

DWORKIN, Ronald (2000). Uma questão de principio. São Paulo, Martins Fontes.

ELSTER, Jon (1993). Sour Grapes. Studies in the subversion of rationality. Cambridge, Cambridge University Press.

ELSTER, Jon (1997). "The Market and the Forum: three varieties of political theory", in James BOHMAN e William REHG (eds.), Deliberative Democracy: Essays on Reason and Politics, Cambridge, The MIT Press. [reproduzido de J Elster e A. Aanund (eds), 1986, Foundations of Social Choice Theory, Cambridge University Press.]

ELSTER, Jon (1998). Deliberative Democracy. Cambridge: Cambridge University Press.

ELSTER, Jon (2000). "Rational choice history: a case of excessive ambition", American Political Science Review, vol. 94, 3, setembro, pp. 685-695..

OLSON, Mancur (1971). The logic of collective action: public goods and the theory of groups. Cambridge, Cambridge University Press.

PETTIT, Philip (1999a). "Republican Freedom and Contestatory Democratization". In Ian Shapiro e Casiano Hacker-Cordón, orgs. (1999) Democracy's Value. Cambridge: Cambridge University Press.

PETTIT, Philip (1999b). Republicanism: a theory of freedom and government. Oxford, Oxford University Press.

PETTIT, Philip (2001). "The Consequentialist perspective”, in Baron, M., P. Petit, e M. Slote, Three methods of ethics. Oxford, Blackwell Publishers.

PRZEWORSKI, Adam (1999). "A minimalist conception of democracy”, in In Ian Shapiro e Casiano Hacker-Cordón, orgs. (1999) Democracy's Value. Cambridge: Cambridge University Press.

RAWLS, John (1999)[1971]. A theory of justice. Cambridge, Cambridge University Press. RAWLS, John (2000), Liberalismo político. São Paulo, Editora Ática.

RAWLS, John (2001a). Justice as fairness: a restatement. Cambridge, The Belknap Press of Harvard University Press.

RAWLS, John (2001b). Direito dos povos. São Paulo, Martins Fontes.

RIKER, William (1983). Liberalism against populism. São Francisco, W.H. Freeman. 
SANDEL, Michael (1996). Democracy's discontent. America in search of a public philosophy. Cambridge, The Belknap Press of Harvard University Press.

SCHUMPETER, Joseph (1975) [1942]. Capitalism, socialism and democracy. Nova York, Harper and Row.

SKINNER, Quentin (1984). “ The idea of Negative liberty: philosophical and historical perspectives", in Richard Rorty, J.B. Schneewind e Q. Skinner, eds., Philosophy in History, Cambridge, Cambridge University Press.

SKINNER, Quentin (1993), "The Republican ideal of political liberty", in G. Bock, Q. Skinner e M Viroli (eds), Machiavelli and Republicanism, Cambridge University Press, 293-309.

SKINNER, Quentin (1999). Liberdade antes do liberalismo. São Paulo, Editora da Unesp.

TAYLOR, Charles (1979). "What's wrong with negative liberty", in Alan Ryan, The Idea of freedom, Oxford, Oxford University Press, 175-193.

TAYLOR, Charles (2000). Argumentações filosóficas. São Paulo, Loyola. 